\title{
Cholera toxin, a typical protein kinase A activator, induces G1 phase growth arrest in human bladder transitional cell carcinoma cells via inhibiting the c-Raf/MEK/ERK signaling pathway
}

\author{
XIAOKE ZHENG ${ }^{1 *}$, YANQIU OU ${ }^{2 *}$, MINFENG SHU ${ }^{3}$, YOUQIONG WANG ${ }^{3}$, YUXI ZHOU ${ }^{3}$, \\ XINGWEN SU ${ }^{3}$, WENBO ZHU ${ }^{3}$, WEI YIN ${ }^{4}$, SHIFENG $\mathrm{LI}^{3}$, PENGXIN QIU ${ }^{3}$, \\ GUANGMEI YAN ${ }^{3}$, JINGXIA ZHANG ${ }^{3}, \mathrm{JUN} \mathrm{HU}^{5}$ and DONG XU ${ }^{3}$ \\ ${ }^{1}$ Department of Pathology, The First Affiliated Hospital, Sun Yat-Sen University, Guangzhou, Guangdong 510089; \\ ${ }^{2}$ Department of Cardiovascular Epidemiology, Guangdong General Hospital, Guangzhou, Guangdong 510080; \\ ${ }^{3}$ Department of Pharmacology, Zhongshan School of Medicine; ${ }^{4}$ Department of Biochemistry, \\ Zhongshan Medical College; ${ }^{5}$ Department of Microbiology, Zhongshan School of Medicine, \\ Sun Yat-Sen University, Guangzhou, Guangdong 510089, P.R. China
}

Received September 10, 2013; Accepted February 19, 2014

DOI: $10.3892 / \mathrm{mmr} .2014 .2054$

\begin{abstract}
The biotoxin cholera toxin has been demonstrated to have anti-tumor activity in numerous types of cancer, including glioma. However, the role of cholera toxin in the tumorigenesis of transitional cell carcinoma (TCC), the most common malignant tumor of the bladder, remains to be elucidated. To address this, in the present study, two TCC cell lines, T24 and UM-UC-3, were treated with cholera toxin [protein kinase A (PKA) activator] and KT5720 (PKA inhibitor). Cell survival and proliferation, cell cycle alterations and apoptosis were analyzed using Hoechst staining, the MTT assay, fluorescence microscopy and flow cytometry. Western blot analysis was used to detect the expression of proteins involved in cell
\end{abstract}

Correspondence to: Dr Dong Xu or Dr Jianxia Zhang, Department of Pharmacology, Zhongshan School of Medicine, Sun Yat-Sen University, 74 Zhongshan Road II, Guangzhou, Guangdong 510089, P.R. China

E-mail: xudong@mail.sysu.edu.cn

E-mail: jianxiaz@163.com

Dr Jun $\mathrm{Hu}$, Department of Microbiology, Zhongshan School of Medicine, Sun Yat-Sen University, 74 Zhongshan Road II, Guangzhou, Guangdong 510089, P.R. China

E-mail: hujun85823@yahoo.com.cn

${ }^{*}$ Contributed equally

Abbreviations: TCC, transitional cell carcinoma; PKA, protein kinase A; Cdk, cyclin-dependent kinase; $\mathrm{Rb}$, retinoblastoma protein

Key words: cholera toxin, bladder cancer, protein kinase A, cell cycle cycle regulation. The results revealed that cholera toxin significantly induced G1 arrest and downregulated the expression of cyclin D1 and cyclin-dependent kinase 4/6 in the TCC cell lines, and this was rescued by KT5720. Furthermore, it was demonstrated that cholera toxin downregulated the activation of the c-Raf/Mek/Erk cascade, an important mediator of tumor cell proliferation, via the PKA-dependent c-Raf phosphorylation at Ser-43. Furthermore, inhibition of Mek activity with UO126 mimicked the effects of cholera toxin. In conclusion, these results confirmed that cholera toxin specifically inhibited proliferation and induced G1 phase arrest in human bladder TCC cells. This effect was due to PKA-dependent inactivation of the c-Raf/Mek/Erk pathway. This suggested that cholera toxin may be a viable therapeutic treatment against tumorigenesis and proliferation in bladder cancer.

\section{Introduction}

Transitional cell carcinoma (TCC), also termed urothelial cell carcinoma, is the most common type of bladder cancer in the United States. It comprises $>90 \%$ of all primary bladder neoplasms. In 2013, there were 70,530 new cases of TCC reported and 14,680 TCC-associated mortalities in the United States (1). Although transurethral resection of the tumor, combined with intravesical bacillus Calmette-Guerin immunotherapy has become the standard treatment for this type of bladder cancer, the tumor recurrence rate remains high (60-70\%). Additionally, the complications of chemotherapy are severe, including frequent micturition, urgent micturition, urination pain, hematuria, immune suppression, febrise and lumbodynia (2).

It is known that patients with bladder cancer have mutations in cell cycle checkpoint genes that are associated with malignant growth and genetic instability. The alteration of multiple cell cycle regulators renders patients with high-grade 
TCC with a survival rate of only $8 \%$ (3). Cell cycle progression is governed by different cyclin-dependent kinases (Cdks) in a step-wise manner, including Cdk4/6 during the G1 phase and Cdk2 from the late G1 phase to the early $\mathrm{S}$ phase. Combined with D-type (D1, D2, D3) cyclin, Cdk4/6 is activated and phosphorylates the retinoblastoma protein $(\mathrm{Rb})$, promoting the escape of E2F from phosphorylated Rb, and therefore inducing cell transit from the $\mathrm{G} 1$ phase into the $\mathrm{S}$ phase. Several previous studies on cell cycle regulation and bladder cancer genetics have demonstrated that the overexpression of cyclin D1 and Cdk4/6 and high levels of phosphorylation of Rb contribute to the dysregulation of the cell cycle during oncogenesis and tumor progression in bladder cancer (4-6).

It has been demonstrated that the mitogen-activated protein kinase (MAPK) cascade (Ras/Raf/Mek/Erk), which induces cyclin and Cdk gene expression and promotes cell cycle progression by activating upstream transcription factors (7), is responsible for TCC oncogenesis and tumor growth (8). Previous studies have demonstrated that the Raf/Mek/Erk cascade is a target for cancer treatment and may be inhibited by the cAMP/protein kinase A (PKA) pathway $(9,10)$. However, whether PKA activators negatively regulate cell proliferation in different types of cancer remains to be elucidated. One of the PKA activators, cholera toxin, has been demonstrated to inhibit pancreatic cancer and leukemia cell growth in vitro, which is dependent upon intracellular cAMP accumulation $(11,12)$. Our previous studies confirmed the ability of PKA activators to inhibit the growth of malignant human glioma cells $(13,14)$. However, the anti-tumor effects of cholera toxin on bladder carcinoma have not yet been clearly demonstrated, therefore, the present study investigated whether targeting PKA with cholera toxin has therapeutic effects against bladder cancer cells.

In the present study, it was hypothesized that cholera toxin may arrest cells in the G1 phase and inhibit cell proliferation in two high-grade invasive cell lines of bladder TCC, T24 and UM-UC-3. Furthermore, it was hypothesized that the inhibition of proliferation by the cholera toxin may be due to PKA-dependent inactivation of the Raf/Mek/Erk pathway and thus, the expression of downstream genes, including cyclin D1, Cdk4 and Cdk6, may be downregulated. Therefore, the present study investigated whether cholera toxin is a potential candidate for anti-cancer treatment with a certain activity on bladder carcinoma.

\section{Materials and methods}

Cell culture and drug treatment. T24 cells were purchased from the Wuhan Cell Bank of China (Wuhan, Hubei, China) and maintained in RPMI-1640 culture medium (Invitrogen Life Technologies, Grand Island, NY, USA) supplemented with $10 \%$ fetal bovine serum (FBS; Invitrogen Life Technologies), $100 \mathrm{U} / \mathrm{ml}$ penicillin and $100 \mathrm{U} / \mathrm{ml}$ streptomycin, in a humidified atmosphere of $5 \% \mathrm{CO}_{2}$ at $37^{\circ} \mathrm{C}$. UM-UC-3 cells were obtained from American Type Culture Collection (Manassas, VA, USA) and maintained in minimum essential medium (Invitrogen Life Technologies). KT5720 and UO126 cells (Calbiochem Bioscience, La Jolla, CA, USA) were dissolved in dimethyl sulfoxide (Sigma, St. Louis, MO, USA) and cholera toxin (Sigma-Aldrich, St. Louis,
MO, USA) was dissolved in sterile ultra-purified water. The cells were plated and allowed to grow overnight in medium containing $10 \%$ FBS. The medium was then replaced with serum-free medium during the treatment.

Cell survival assay. Cell viability was evaluated using the 3-(4,5-dimethylthiazol-2-yl)-2,5-diphenyl tetrazolium bromide (MTT) assay (Sigma). The optical density (OD) was determined at $570 \mathrm{~nm}$ using an EXL800 microimmunoanalyzer (Bio-Tek Instruments, Burlington, VT, USA). The cell viability rate was calculated using the following formula: $\mathrm{OD}_{\text {experiment }} / \mathrm{OD}_{\text {control }} \mathrm{x} 100 \%$.

Cell proliferation and clone formation assay. The cells were placed in a six-well plate at a density of 500 cells/well and maintained with or without $10 \mathrm{ng} / \mathrm{ml}$ cholera toxin in normal medium containing $10 \%$ FBS for 10 days. Colonies were fixed with methanol and stained with $0.1 \%$ crystal violet in $20 \%$ methanol for $15 \mathrm{~min}$ and images of the representative colonies were captured.

Hoechst staining and lactate dehydrogenase $(\mathrm{LDH})$ release assay. For Hoechst 33342 staining, the cells were incubated with Hoechst 33342 (5 $\mu \mathrm{g} / \mathrm{ml}$; Sigma) for $20 \mathrm{~min}$ in the dark and then observed using a fluorescent microscope (Olympus, Melvie, NY, USA) with a $340 \mathrm{~nm}$ excitation filter.

Cytotoxicity of diazepam was evaluated using the $\mathrm{LDH}$ release assay. $\mathrm{LDH}$ release was quantified using a CytoTox $96^{\circledR}$ nonradioactive cytotoxicity assay kit (Promega Corporation, Madison, WI, USA) in accordance with the manufacturer's instructions. Absorbance was measured at 490 nm using an iMark ${ }^{\mathrm{TM}}$ Microplate Absorbance Reader (Bio-Rad, Hercules, CA, USA). Lysis solution was used as a positive control for maximum $\mathrm{LDH}$ release. To calculate the $\%_{\text {Cytotoxicity }}$ of each treatment group, the following formula was used, in accordance with the manufacturer's instructions: $\%_{\text {Cytotoxicity }}=$ Experimental LDH release $(O D 490) /$ Maximum $\mathrm{LDH}$ release (OD490). The $\mathrm{LDH}$ release $\left(\%_{\text {control }}\right)$ was calculated as the $\%_{\text {Cytotoxicity }}$ of the treatment group over the $\%_{\text {Cytotoxicity }}$ of the vehicle control $(0 \mu \mathrm{M})$ group.

Cell cycle analysis. The cells were seeded in six-well culture plates at a density of $8 \times 10^{5}$ cells/well and incubated overnight. Cholera toxin $(0-50 \mathrm{ng} / \mathrm{ml})$ was added to the serum-free medium for $0-24 \mathrm{~h}$. The cells were harvested by trypsinization, suspended in $100 \mu 1$ medium and then fixed in $75 \%$ dehydrated alcohol overnight in $4^{\circ} \mathrm{C}$. The cells were subsequently incubated with the DNA-binding dye propidium iodide (PI; $50 \mathrm{mg} / \mathrm{ml}), \mathrm{RNase}(4 \mathrm{Ku} / \mathrm{ml}), \mathrm{NaF}(0.3 \mathrm{mg} / \mathrm{ml})$ and sodium citrate $(1 \mathrm{mg} / \mathrm{ml})$ for $1-2 \mathrm{~h}$ at room temperature in the dark. Red fluorescence from $488 \mathrm{~mm}$ laser-excited PI in every cell was analyzed using an EPICS Altra flow cytometer (Beckman Coulter, Fullerton, CA, USA) using a peak fluorescence gate to discriminate aggregates. The percentage of cells in the G1, S and G2/M phases were determined from the DNA content histograms using MultiCycle for windows software (Phoenix Flow Systems, San Diego, CA, USA).

Raf kinase assay and western blot analysis. The Raf kinase assay kit was purchased from Upstate Biotechnology 


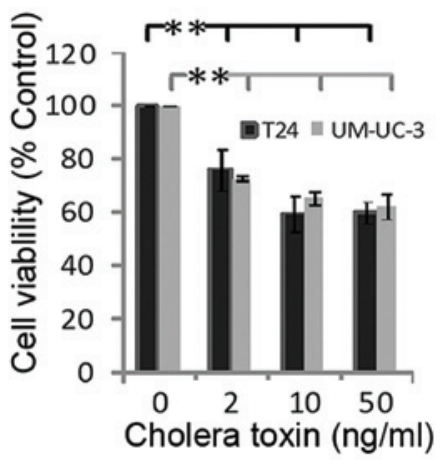

C

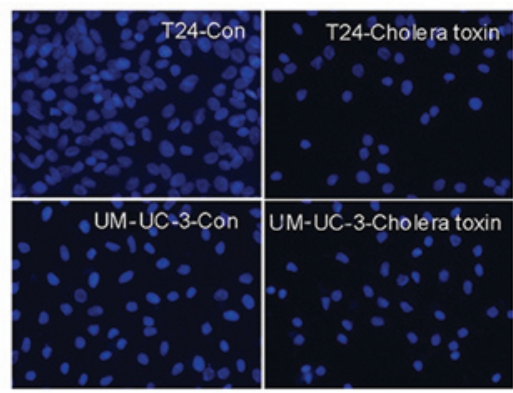

T24

D

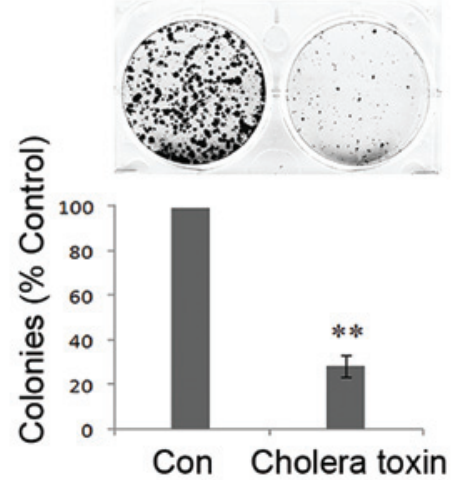

B
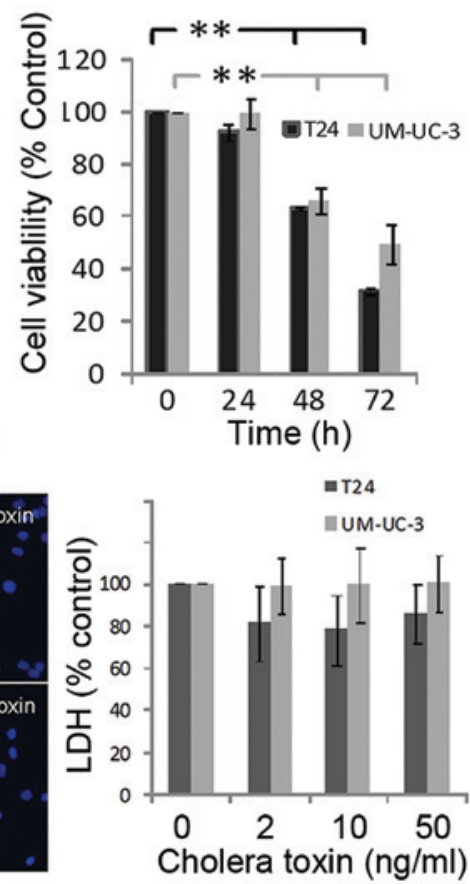

UM-UC-3

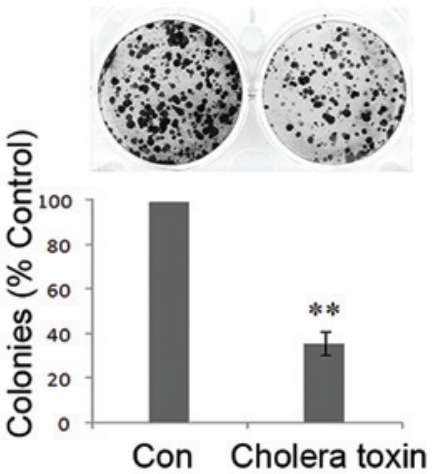

Figure 1. Cholera toxin inhibits proliferation and arrests the cell cycle in the G1 phase without notable proapoptotic or toxic effects in human TCC cell lines (A) Cholera toxin inhibited T24 and UM-UC-3 cell viability in a dose-dependent manner. The cells were incubated with cholera toxin for 48 h. (B) Cholera toxin inhibited T24 and UM-UC-3 cells viability in a time-dependent manner. The cells were incubated with $10 \mathrm{ng} / \mathrm{ml}$ cholera toxin for the indicated time period. (C) Cholera toxin induced neither apoptosis nor necrosis in T24 and UM-UC-3 cells. The cells were treated with $10 \mathrm{ng} / \mathrm{ml}$ cholera toxin for $72 \mathrm{~h}$ and subjected to fluorescent staining of nuclei (left). The cells were treated with cholera toxin for $72 \mathrm{~h}$ and the absorbance of lactate dehydrogenase (\% control) is shown. (D) Cholera toxin decreased cell colony formation. The two cell lines were incubated with $10 \mathrm{ng} / \mathrm{ml}$ cholera toxin for 10 days. ${ }^{* *} \mathrm{P}<0.01$.

(Charlottesville, VA, USA) and used in accordance with the manufacturer's instructions. Western blot analysis was performed as previously described and the blots were visualized by peroxidase reaction using enhanced chemiluminescence (Amersham Pharmacia Biotech, Piscataway, NJ, USA) (15). The following antibodies were used: cyclin D1, cyclin D3, Cdk4, Cdk6, p-Rb ${ }^{\text {Ser807/Ser811, }}$ c-Raf, p-c-Raf ${ }^{\text {Ser259 }}$, B-Raf, p-B-Raf ${ }^{\text {Ser } 445}$, p-Mek $1 / 2^{\text {Ser217/221, }}$, Mek, p-Erk1/2 ${ }^{\mathrm{Thr} 202 / \mathrm{Ty} 204}$, Erk and GAPDH (Cell Signaling Technology, Beverly, MA, USA); cyclin E, Cdk2 and Rb (Santa Cruz Biotechnology, Inc., Santa Cruz, CA, USA) and p-c-Raf ${ }^{\mathrm{Ser} 43}$ and p-c-Raf ${ }^{\mathrm{Ser} 621}$ (Abcam, Cambridge, MA, USA); $\beta$-actin (Neomarker, Fremont, CA, USA) and $\alpha$-tubulin (Sigma). The blots are representative of three independent experiments.
Statistical analysis. Statistical analysis was performed using PASS 11 (NCSS, LLC, Kaysville, Utah, USA) using one way analysis of variance. $\mathrm{P}<0.05$ was considered to indicate a statistically significant difference.

\section{Results}

Cholera toxin inhibits proliferation and arrests the cell cycle in the G1 phase of human bladder TCC cells. The effect of cholera toxin on human bladder TCC cell growth was investigated. As shown in Fig. 1A, the viability of T24 and UM-UC-3 cells decreased following incubation with the cholera toxin (between 2 and $50 \mathrm{ng} / \mathrm{ml}$ ) for $48 \mathrm{~h}$. The inhibitory effect of cholera toxin $(10 \mathrm{ng} / \mathrm{ml})$ increased time dependently between 24 and 72 h (Fig. 1B) in the two cell 
lines. However, cell apoptosis and cell necrosis were not detected at $72 \mathrm{~h}$ (Fig. 1C). In combination with the result that fewer and smaller colonies are observed when cells are incubated with $10 \mathrm{ng} / \mathrm{ml}$ cholera toxin for 10 days (Fig. 1D), these results indicated that cholera toxin significantly inhibited T24 and UM-UC-3 cell proliferation in a dose- and time-dependent manner.

To further investigate the mechanism underlying the anti-proliferative activity of cholera toxin, its effect on cell cycle distribution was investigated using flow cytometry. In cholera toxin-treated T24 cells there was an accumulation of $93.4,94.5$ and $94.5 \%$ cells, respectively, in the G1 phase following $24 \mathrm{~h}$ incubation with cholera toxin at 2, 10 and $50 \mathrm{ng} / \mathrm{ml}$, respectively, compared with the control group comprising of $78.5 \%$ cells. This was accompanied by a decrease in the proportion of cells in the $\mathrm{S}$ phase (Fig. 2A). In the time-response study, an increase in the percentage of cells in the G1 phase was observed with $10 \mathrm{ng} / \mathrm{ml}$ cholera toxin treatment for $12(\mathrm{P}<0.05)$ and $24 \mathrm{~h}(\mathrm{P}<0.001)$ compared with the control cells (Fig. 2B).

Incubation with cholera toxin at 2, 10 and $50 \mathrm{ng} / \mathrm{ml}$ for $24 \mathrm{~h}$, resulted in an increase in the number of UM-UC-3 cells in the G1 phase to $75.5,76.9$ and $77.3 \%$, respectively, compared with $65.1 \%$ observed in the control cells (Fig. 2A). However, the effect of cholera toxin was weaker in UM-UC-3 cells compared with T24 cells. Similar to T24 cells, the effect of cholera toxin on G1 arrest in UM-UC-3 cells was also largely accompanied by a decrease in $\mathrm{S}$ phase cells (Fig. 2B). Overall, these results demonstrated that cholera toxin induced a significant $\mathrm{G} 1$ arrest of the cell cycle in T24 and UM-UC-3 cells.

Cholera toxin downregulates the G1-S transition promoters in human TCC cells. Based on the G1 phase arrest induced by cholera toxin in T24 and UM-UC-3 cells, the expression of cell cycle regulatory molecules involved in G1 phase progression was then investigated. Cell cycle progression through the G1 phase is primarily regulated by the sequential activation of the cyclin D-Cdk4/6 and cyclin E-Cdk2 complexes, which induce $\mathrm{Rb}$ phosphorylation and E2F release. However, Cdk1 (e.g. p27 ${ }^{\text {Kipl }}$ ) is capable of deactivating the cyclin D-Cdk4/6 and cyclin E-Cdk2 complexes and thus decreases the phosphorylation of $\mathrm{Rb}$ (16). In the present study, it was found that cholera toxin was able to notably reduce the protein expression levels of cyclin D1, Cdk4 and Cdk6 in a dose- and time-dependent manner. In addition, $\mathrm{Rb}$ phosphorylation markedly decreased in the two cell lines (Fig. 2A and B). However, cholera toxin was not observed to have an effect on other G1 regulators, including cyclin D3, cyclin E, Cdk2 and P27 ${ }^{\mathrm{Kip} 1}$ (data not shown). These results suggested that cholera toxin reduces the activation of $\mathrm{Rb}$ by downregulating the expression of cyclin D1, Cdk4 and Cdk6 thus inducing G1 phase arrest.

PKA activity is required for cholera toxin-induced G1 phase arrest and downregulation of G1-S transition promoters. Our previous studies confirmed that PKA activators, cholera toxin or forskolin, repressed cell growth via cell cycle arrest in the G1 phase in malignant glioma cells via PKA activation $(13,14)$. To examine whether PKA activation is also involved in the G1 growth arrest of cholera toxin in T24 and UM-UC-3 cells, a specific pharmacological inhibitor of PKA, KT5720, was used.
As shown in Fig. 3A, pretreatment with KT5720 $(1 \mu \mathrm{M})$ for $2 \mathrm{~h}$ eradicated cholera toxin-induced G1 phase arrest in the two cell lines. Decreased expression levels of cyclin D1, Cdk4 and Cdk6, as well as the reduced phosphorylation of Rb due to cholera toxin, were rescued by KT5720 pretreatment (Fig. 3B). This indicated that in TCC cell lines T24 and UM-UC-3, PKA stimulation was responsible for the cholera toxin-induced downregulation of G1-S transition promoters and G1 phase arrest.

PKA-dependent inactivation of the c-Raf/Mek/Erk pathway mediates $G 1$ phase arrest. A number of pathways are involved in the regulation of cell proliferation, including the c-Raf/Mek/Erk pathway, and functions via activation of multiple transcription factors, which switch on their target genes, for example cyclin D1 (7). To further investigate the mechanism by which cholera toxin inhibits proliferation and arrests cells in the G1 phase in the two TCC cell lines, the level of c-Raf phosphorylation was assessed at serine 43, 259 and 621 following cholera toxin treatment for $24 \mathrm{~h}$. The result demonstrated that the phosphorylation of serine 43 by c-Raf was elevated by cholera toxin in a time-dependent manner (Fig. 4A).

The activity of the c-Raf/Mek/Erk pathway was then detected using the Raf kinase assay and western blot analysis. As shown in Fig. 4B, c-Raf activity was attenuated in cholera toxin-treated T24 and UM-UC-3 cells. Among the four major MAPK modules, ERK5/p38/JNK/Erk1/2, the one converging on the activation of ERK and its upstream activator MAPK and ERK kinase (MEK) is the most extensively studied and perhaps the most relevant to cancer pathogenesis and therapy. p-Mek1/2 ${ }^{\text {Ser217/221 }}$ and p-Erk1/2 ${ }^{\text {Thr202/Tyr204 }}$ are markers of activated Mek1/2 and Erk1/2 and were found to be time-dependently downregulated in response to $10 \mathrm{ng} / \mathrm{ml}$ cholera toxin. Furthermore, KT5720 significantly inhibited c-Raf phosphorylation at serine 43 and upregulated the expression of $\mathrm{p}-\mathrm{Mek}^{\mathrm{Ser} 217 / 221}$ and $\mathrm{p}-\mathrm{Erk}^{\mathrm{Thr} 202 / \mathrm{Tyr} 204}$ in T24 and UM-UC-3 cells (Fig. 4C). These results demonstrated that PKA activation was required for the inactivation of the c-Raf/Mek/Erk pathway by cholera toxin.

To further identify the role of the c-Raf/Mek/Erk pathway in G1-S phase transition and cell proliferation, UO126, a specific inhibitor of Mek activity, was used. Treatment with $1 \mu \mathrm{M}$ UO126 for $24 \mathrm{~h}$ arrested the cell cycle in the G1 phase, accompanied by a decrease in cell population in the $\mathrm{S}$ phase in T24 and UM-UC-3 cells (Fig. 4D). In addition, the expression of p-Erk ${ }^{\mathrm{Thr} 202 / \mathrm{Tyr} 204}$, cyclin D1, Cdk4, Cdk6 and p-Rb was downregulated in UO126-treated cells (Fig. 4E). The effect of UO126 on the two cell lines is consistent with cholera toxin. This suggested that the inactivation of the c-Raf/Mek/Erk pathway is responsible for cholera toxin-induced decreases in cyclin D1, Cdk4 and Cdk6 and results in G1 phase arrest.

\section{Discussion}

In the present study, the biological effect of cholera toxin in two bladder TCC cell lines was investigated. The results demonstrated that cholera toxin markedly induced G1 phase arrest and inhibited cell proliferation in two human invasive bladder TCC cell lines. However, no growth-inhibitory effect of cholera toxin 
A

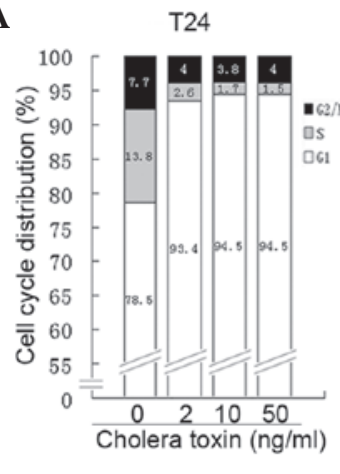

Cholera toxin $(\mathrm{ng} / \mathrm{ml})$

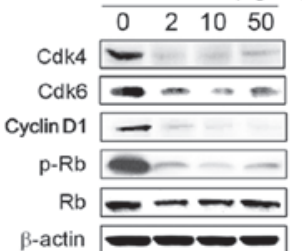

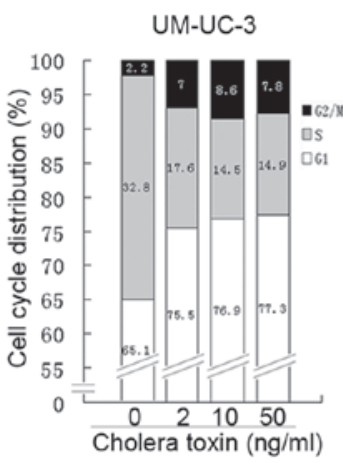

Cholera toxin (ng/ml)

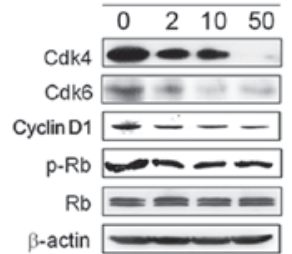

B $\quad \mathrm{T} 24$

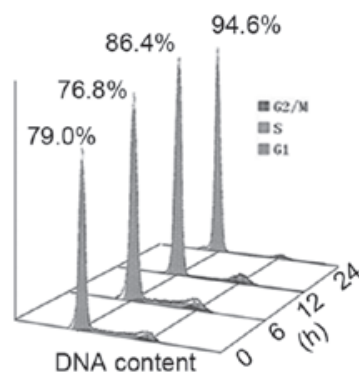

Cholera toxin $(10 \mathrm{ng} / \mathrm{ml})$

\begin{tabular}{lllll}
\hline 0 & 6 & 12 & 24 & $(h)$
\end{tabular}

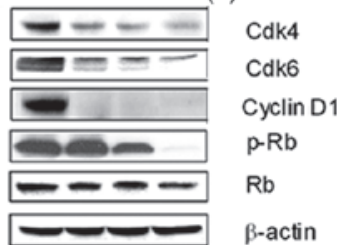

UM-UC-3 $\quad 77.9 \%$

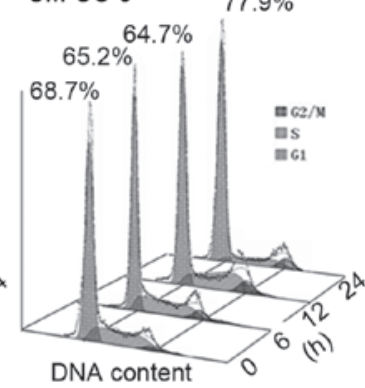

Cholera toxin $(10 \mathrm{ng} / \mathrm{ml})$ $\begin{array}{lllll}0 & 6 & 12 & 24 & \text { (h) }\end{array}$

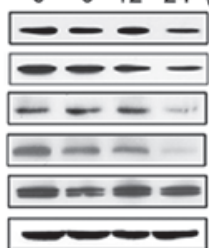

Cdk4

Cdk6

Cyclin D1

$\mathrm{p}-\mathrm{Rb}$

$\mathrm{Rb}$

$\beta$-actin

Figure 2. Cholera toxin induces cell cycle arrest and downregulates cell cycle regulatory molecules in human transitional cell carcinoma cell lines. (A) G1 phase and cyclin D1, Cdk4, 6 and p-Rb of T24 and UM-UC-3 cells were modulated by cholera toxin dose dependently. The cells were exposed to the indicated concentration of cholera toxin for $24 \mathrm{~h}$. (B) G1 phase and cyclin D1, Cdk4, 6 and p-Rb of T24 and UM-UC-3 cells were modulated by cholera toxin time dependently. The cells were incubated with $10 \mathrm{ng} / \mathrm{ml}$ cholera toxin for the indicated time periods. Cdk, cyclin-dependent kinase; Rb, retinoblastoma protein.

A

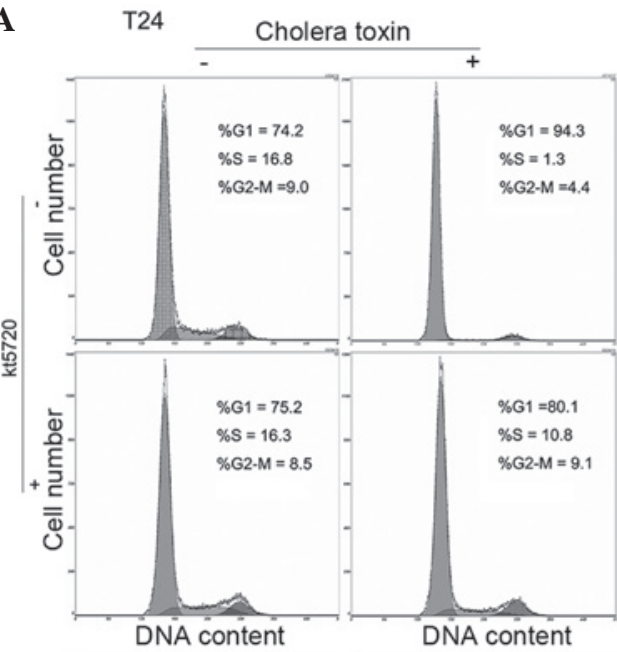

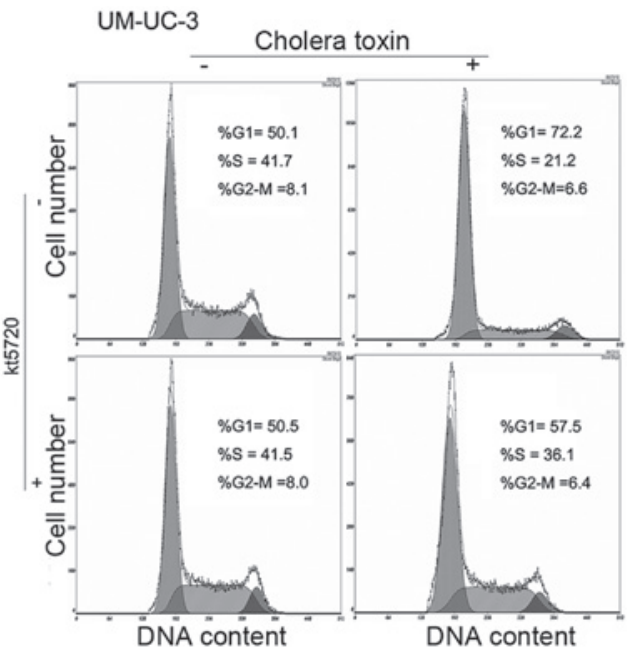

B

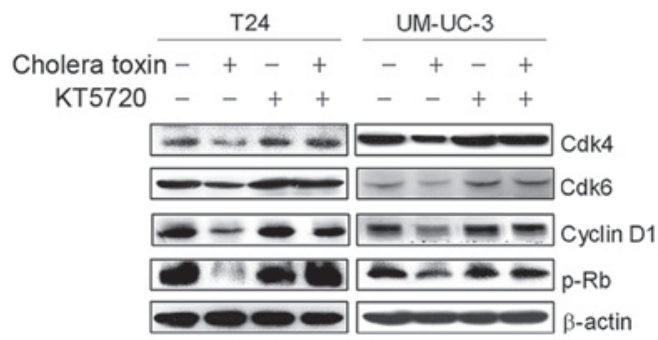

Figure 3. Protein kinase A activity is required for cholera toxin-induced G1 phase arrest and the downregulation of G1-S transition promoters. (A) KT5720 reversed the G1 phase arrest induced by cholera toxin in human TCC cell lines. (B) KT5720 rescued the expression of cell cycle regulatory molecules induced by cholera toxin in human TCC cell lines. T24 and UM-UC-3 cells were pretreated with $1 \mu \mathrm{M} \mathrm{KT5720} \mathrm{for} 2 \mathrm{~h}$ and then exposed to $10 \mathrm{ng} / \mathrm{ml}$ cholera toxin for an additional $24 \mathrm{~h}$. TCC, transitional cell carcinoma.

was observed in non-tumorigenic urothelium SV-HUV-1 cells (data not shown). This indicates that cholera toxin functions as a selective inhibitor of TCC cell proliferation, however, not normal bladder uroepithelial cell proliferation.
Tumorigenesis and the progression of bladder cancer is considered to be closely associated with the dysregulation of multiple cell cycle modulators (8), including Cdk4, cyclin D1 and $\mathrm{p}-\mathrm{Rb}$, and these cell cycle regulators are regarded as 
A

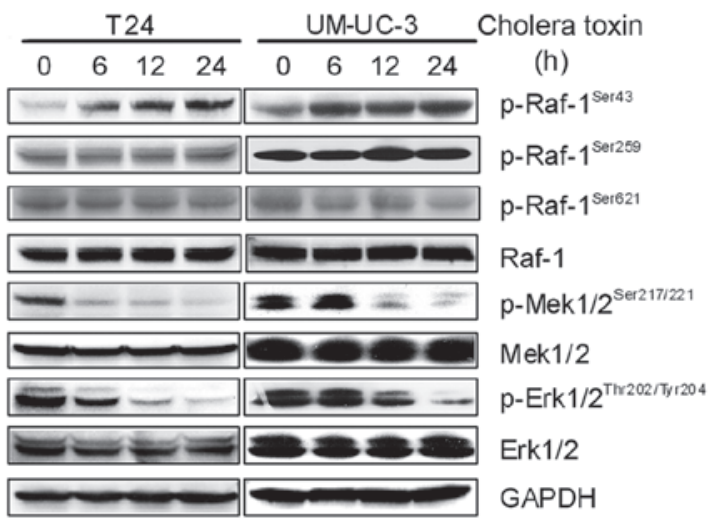

B

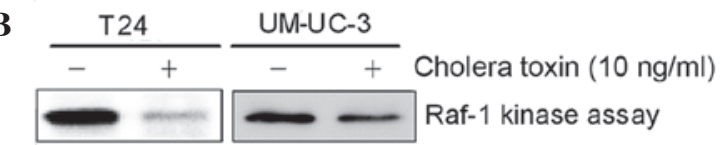

C

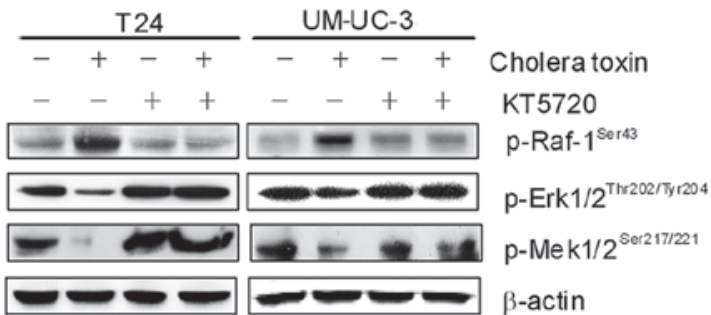

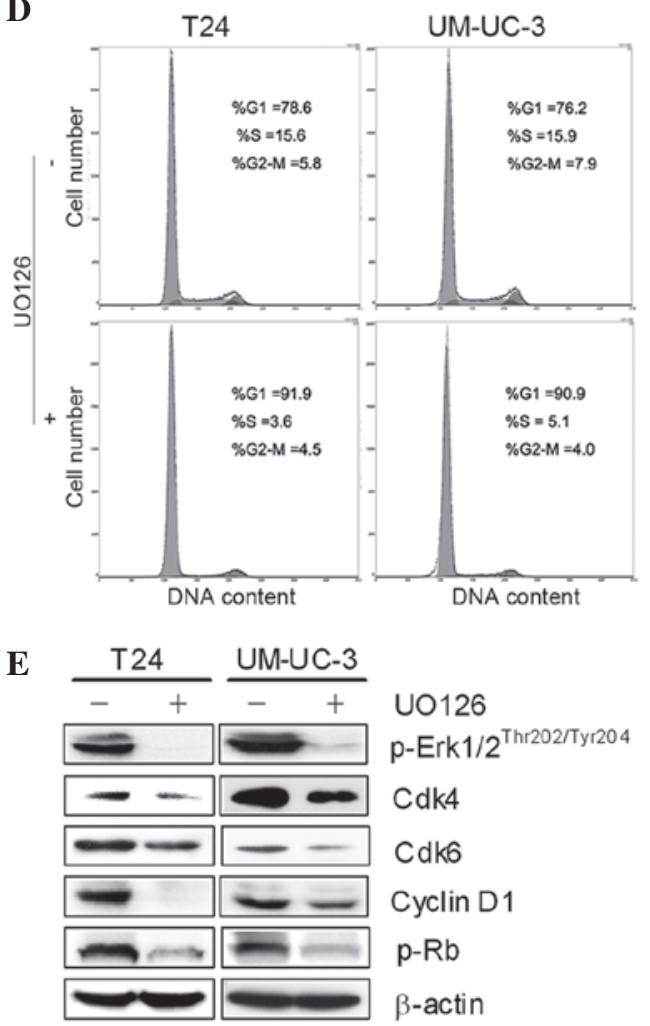

Figure 4. Protein kinase A-dependent inactivation of the c-Raf/Mek/Erk pathway mediates the effects of cholera toxin. (A) c-Raf/Mek/Erk pathway was inactivated by cholera toxin. T24 and UM-UC-3 cells were incubated with $10 \mathrm{ng} / \mathrm{ml}$ cholera toxin for the indicated time and molecules involved in the c-Raf/Mek/Erk pathway (e.g. p-c-Raf ${ }^{\text {Ser43 }}$, p-c-Raf ${ }^{\text {Ser259 }}$, p-c-Raf ${ }^{\text {Ser621 }}, c-R a f, p-M e k 1 / 2^{\text {Ser217/221 }}$, p-Erk1/2 ${ }^{\text {Thr202/Tyr204 }}$, Mek and Erk) were measured. (B) Raf-1 activity was downregulated by cholera toxin. T24 and UM-UC-3 cells were incubated with or without $10 \mathrm{ng} / \mathrm{ml}$ cholera toxin for $6 \mathrm{~h}$. (C) KT5720 rescued the c-Raf/Mek/Erk pathway inactivation induced by cholera toxin in human transitional cell carcinoma cell lines. T24 and UM-UC-3 cells were pretreated with $1 \mu \mathrm{M}$ KT5720 for $2 \mathrm{~h}$ and then subjected to $10 \mathrm{ng} / \mathrm{ml}$ cholera toxin for an additional $24 \mathrm{~h}$. (D and E) Inhibition of Mek activity mimicked the cell cycle arrest observed in cells treated with cholera toxin. T24 and UM-UC-3 cells were incubated with $1 \mu \mathrm{M}$ UO126 for $24 \mathrm{~h}$

prognostic indicators of bladder cancer progression (17). The amplification of the CDK4/6 gene occurs more frequently in higher stage/grade bladder cancer (4). Cdk4/6 and cyclin D1 are also significantly correlated with the recurrence of bladder cancer $(5,18)$. In the present study, it was demonstrated that cholera toxin simultaneously downregulated cyclin D1, Cdk4 and Cdk6, and markedly decreased the phosphorylation of $\mathrm{Rb}$, therefore inhibiting cell cycle progression and cell proliferation in the bladder TCC cell lines.

Approximately $82 \%$ of grade one bladder cancers show constitutive activation of the RAF/MEK/ERK pathways. The crosstalk between cAMP/PKA and RAF/MEK/ERK pathways in cell death, proliferation and differentiation is known to be important. Our previous study demonstrated that cholera toxin inhibited proliferation and induced cell-cycle arrest in glioma cells by downregulating cyclin D1, and that the PKA/CREB pathway was involved (13). In the present study, the anti-proliferative mechanism of cholera toxin in bladder TCC cells was consistent with previous results. It was revealed that cholera toxin inactivated the c-Raf/Mek/Erk cascade and downregulated the expression of the regulatory molecules (cyclin D1, Cdk4 and Cdk6), in a PKA-dependent manner.

The RAF/MEK/ERK pathway has recently emerged as a promising target for anticancer therapies, as excessive activation of this pathway is often observed in various types of tumor (19). PKA negatively regulates the activity of c-Raf and functions as an inhibitor of the c-Raf/Mek/Erk pathway via c-Raf. The phosphorylation of c-Raf in several inhibitory sites by PKA, for example phosphorylation at ser 43, disrupts the Ras/c-Raf association, inactivates c-Raf, inhibits the cRaf/Mek/Erk pathway and finally inhibits cell growth $(20,21)$. In the present study, an increase in c-Raf phosphorylation at ser 43 by cholera toxin, and consequently the inactivation of c-Raf/Mek/Erk, was observed in T24 and UM-UC-3 cells. Sorafenib, an FDA-approved agent for the treatment of human hepatocellular carcinoma (HCC), has been demonstrated to inhibit HCC cell growth by also inducing c-Raf phosphorylation at Ser-43 and Ser-259 (22).

Furthermore, UO126, the specific Mek inhibitor, induced the downregulation of cyclin D1, Cdk4 and Cdk6 in T24 and UM-CU-3 cells, which is consistent with the effect of cholera toxin. All these data indicated that deactivation of the c-Raf/Mek/Erk cascade by PKA was, at least partially responsible for the downregulation of cyclin D1, Cdk4 and Cdk6 and cell cycle arrest in the G1 phase by cholera toxin.

In summary, in the present study, it was confirmed that cholera toxin specifically inhibited cell proliferation and induced G1 phase arrest in human bladder TCC cells. This tumor inhibitory effect was revealed to be due to the PKA-dependent inactivation of the c-Raf/Mek/Erk pathway and a marked reduction of cyclin D1, Cdk4 and Cdk6. These findings support the use of cholera toxin in target specific therapy for the treatment of bladder cancer. 


\section{Acknowledgements}

This study was supported by the National Natural Science Foundation of China (nos. 30830111, 81202554 and 81202555 ) and the Guangdong Natural Science Foundation (S10451008901004893 and S2012010009237).

\section{References}

1. Siegel R, Naishadham D and Jemal A: Cancer statistics, 2013. CA Cancer J Clin 63: 11-30, 2013.

2. Shelley MD, Mason MD and Kynaston H: Intravesical therapy for superficial bladder cancer: a systematic review of randomised trials and meta-analyses. Cancer Treat Rev 36: 195-205, 2010

3. Chatterjee SJ, Datar R, Youssefzadeh D, et al: Combined effects of p53, p21, and pRb expression in the progression of bladder transitional cell carcinoma. J Clin Oncol 22: 1007-1013, 2004.

4. Simon R, Struckmann K, Schraml P, et al: Amplification pattern of 12q13-q15 genes (MDM2, CDK4, GLI) in urinary bladder cancer. Oncogene 21: 2476-2483, 2002

5. Shin KY, Kong G, Kim WS, Lee TY, Woo YN and Lee JD: Overexpression of cyclin D1 correlates with early recurrence in superficial bladder cancers. Br J Cancer 75: 1788-1792, 1997.

6. Chatterjee SJ, George B, Goebell PJ, et al: Hyperphosphorylation of $\mathrm{pRb}$ : a mechanism for RB tumour suppressor pathway inactivation in bladder cancer. J Pathol 203: 762-770, 2004.

7. Chang F, Steelman LS, Lee JT, et al: Signal transduction mediated by the Ras/Raf/MEK/ERK pathway from cytokine receptors to transcription factors: potential targeting for therapeutic intervention. Leukemia 17: 1263-1293, 2003.

8. Mitra AP and Cote RJ: Molecular pathogenesis and diagnostics of bladder cancer. Annu Rev Pathol 4: 251-285, 2009.

9. Sevetson BR, Kong X and Lawrence JC Jr: Increasing cAMP attenuates activation of mitogen-activated protein kinase. Proc Natl Acad Sci USA 90: 10305-10309, 1993.
10. Roberts PJ and Der CJ: Targeting the Raf-MEK-ERK mitogen-activated protein kinase cascade for the treatment of cancer. Oncogene 26: 3291-3310, 2007.

11. Pessina A, Giuliani A, Croera C, et al: Selection of a WEHI-3B leukemia cell subclone resistant to inhibition by cholera toxin. Mol Cell Biochem 233: 19-26, 2002.

12. Ohmura E, Wakai K, Isozaki O, et al: Inhibition of human pancreatic cancer cell (MIA PaCa-2) growth by cholera toxin and 8-chloro-cAMP in vitro. Br J Cancer 67: 279-283, 1993.

13. Li Y, Yin W, Wang X, Zhu W, Huang Y and Yan G: Cholera toxin induces malignant glioma cell differentiation via the PKA/CREB pathway. Proc Natl Acad Sci USA 104: 13438-13443, 2007.

14. He S, Zhu W, Zhou Y, et al: Transcriptional and post-transcriptional down-regulation of cyclin D1 contributes to C6 glioma cell differentiation induced by forskolin. J Cell Biochem 112: 2241-2249, 2011.

15. Kurien BT and Scofield RH: Western blotting. Methods 38: 283-293, 2006.

16. Malumbres M and Barbacid M: Cell cycle, CDKs and cancer: a changing paradigm. Nat Rev Cancer 9: 153-166, 2009.

17. Mitra AP, Lin H, Datar RH and Cote RJ: Molecular biology of bladder cancer: prognostic and clinical implications. Clin Genitourin Cancer 5: 67-77, 2006.

18. Weinberg RA: The retinoblastoma protein and cell cycle control. Cell 81: 323-330, 1995.

19. McCubrey JA, Steelman LS, Chappell WH, et al: Roles of the Raf/MEK/ERK pathway in cell growth, malignant transformation and drug resistance. Biochim Biophys Acta 1773 1263-1284, 2007.

20. Wu J, Dent P, Jelinek T, Wolfman A, Weber MJ and Sturgill TW: Inhibition of the EGF-activated MAP kinase signaling pathway by adenosine 3',5'-monophosphate. Science 262: 1065-1069, 1993

21. Stork PJ and Schmitt JM: Crosstalk between cAMP and MAP kinase signaling in the regulation of cell proliferation. Trends Cell Biol 12: 258-266, 2002.

22. Carr BI, Wang Z, Wang M, Cavallini A, D'Alessandro R and Refolo MG: c-Met-Akt pathway-mediated enhancement of inhibitory c-Raf phosphorylation is involved in vitamin $\mathrm{K} 1$ and sorafenib synergy on HCC growth inhibition. Cancer Biol Ther 12: 531-538, 2011. 